\section{AINA NEWS}

\section{Associate Director of AINA Appointed}

Dr. Brent Else joined AINA in fall 2020, as the new Associate Director. He will provide support for the Institute's Executive Director, Dr. Maribeth Murray, with tasks related to AINA's strategic plan. He will help establish bilateral partnerships with organizations who share similar objectives, support and lead grant applications, connect University of Calgary researchers to AINA initiatives, and support AINA's Observer status at Arctic Council. Dr. Else is an Associate Professor in the Department of Geography, University of Calgary, and leads an active research group studying greenhouse gas cycling in Arctic marine environments. He leads several major national projects studying Arctic marine biogeochemistry, including an ArcticNet-funded project based on the CCGS Amundsen, and a Marine Environmental Observation, Prediction and Response Network-funded project based out of Cambridge Bay, Nunavut. In Cambridge Bay, Dr. Else has worked with local community groups to build a weather station network

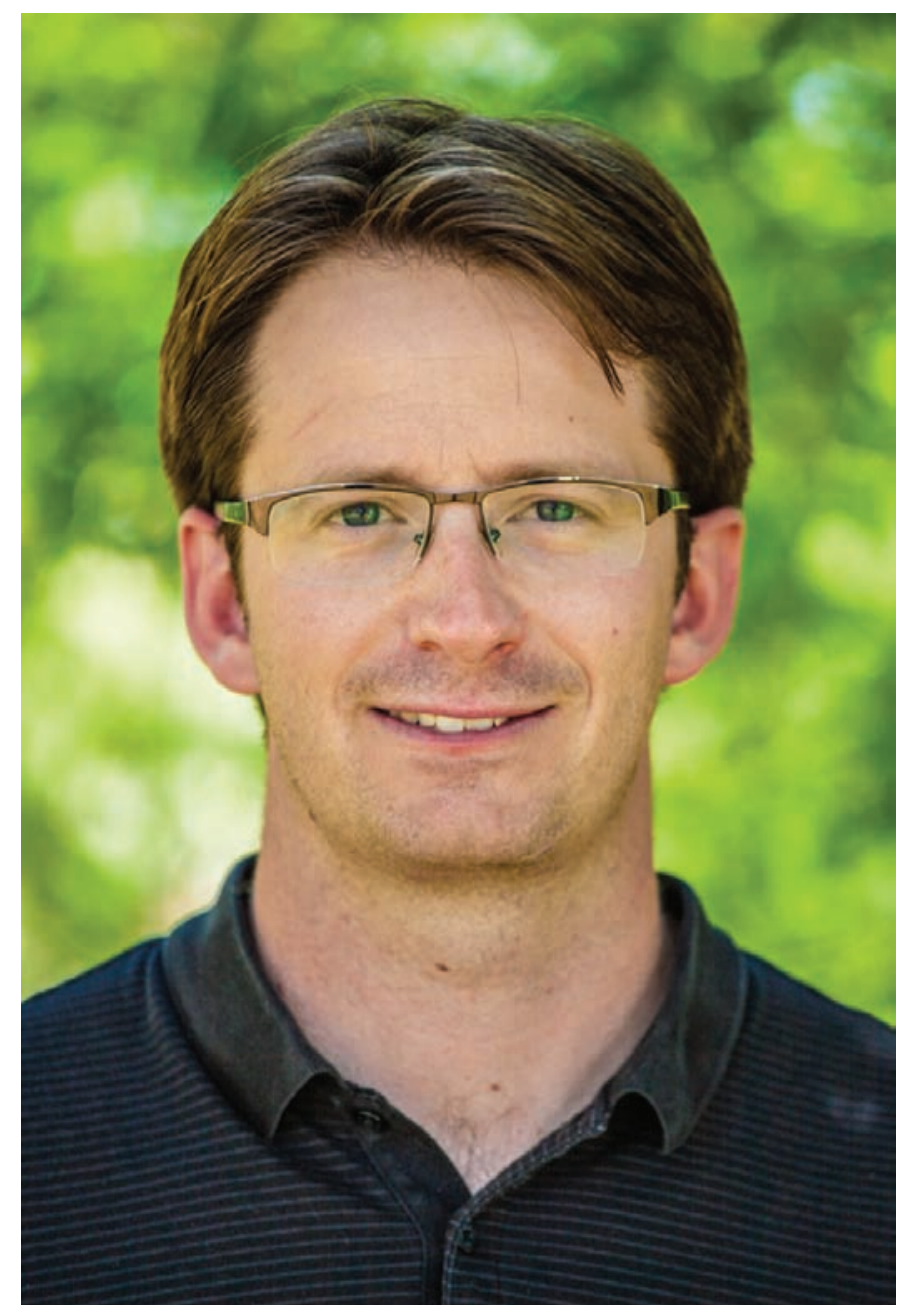

and to develop training programs for graduates of Nunavut Arctic College's Environmental Technology diploma. Dr. Else was raised in Calgary, Alberta, and completed undergraduate and master's degrees at the University of Calgary. He completed his $\mathrm{PhD}$ at the University of Manitoba in the Department of Environment and Geography before returning to Calgary in 2014. Dr. Else loves to go camping and fishing with his family in beautiful southern Alberta.

\section{Scholarship Winners}

Claire Singer, a PhD student in the Environmental Science Department at Saint Mary's University in Halifax, is the 2021 recipient of the Lorraine Allison Memorial Scholarship. Her research will investigate plant distribution shifts within the Northwest Territories (NWT) as a result of changing climatic conditions and human-assisted introduction, and the implications of this for native plant and soil communities. Sampling will occur in the southern NWT along roads and rivers, and in road-adjacent burns.

Willow English, a Master of Science student in the Department of Biology at Carleton University is the 2021 recipient of the Jennifer Robinson Memorial Scholarship. Her research focuses on Arctic-breeding shorebirds, a group of long-distance migrants that are suffering from widespread declines. She uses tracking technology and physiological markers to follow individuals over the entire year and to better understand how environmental conditions continue to affect birds throughout the year as they move across the globe. The goal of her research is to identify priority locations and optimal times of year for conservation action.

\section{Training Program Grant Announcement}

AINA administers student applications for the Northern Science Training Program (NSTP) at the University of Calgary. NSTP is a program within Polar Knowledge Canada designed to defray the high costs of travel for students conducting research in the Arctic and subarctic regions. This year ten students were successful in their applications and will share the $\$ 42602$ allocated to the university. They are Kelsey Pennanen, Erica Suitor, Kaylee Baxter, Christina Braybrook, Megan Leung, Cecilia Porter, Rory Armstrong, Kristina Miller, Aaron Irving, and Gillian Taylor. 